\title{
Identification of BRAF p. V600E-Mutant and Wild-Type by MR Imaging in Pleomorphic Xanthoastrocytoma and Anaplastic Pleomorphic Xanthoastrocytoma
}

\author{
(D)W. Huang, (D). Cai, (D) N. Lin, (D) Y. Xu, (D) H. Wang, (D) Z. Wu, and DD. Kang
}

\begin{abstract}
BACKGROUND AND PURPOSE: Compared with BRAF p. V600E wild-type pleomorphic xanthoastrocytoma, BRAF p. V600E-mutant pleomorphic xanthoastrocytoma showed a higher survival rate. In this study, we focused on finding preoperative MR imaging differences between BRAF p. V600E mutant and wild-type in pleomorphic xanthoastrocytoma and anaplastic pleomorphic xanthoastrocytoma.

MATERIALS AND METHODS: Twenty-three patients with pathologically confirmed pleomorphic xanthoastrocytoma or anaplastic pleomorphic xanthoastrocytoma in our hospital were retrospectively analyzed from January 2015 to December 2020. They were divided into a BRAF p. V600E-mutant group (including 6 pleomorphic xanthoastrocytomas and 5 anaplastic pleomorphic xanthoastrocytomas) and a wild-type group (including 8 pleomorphic xanthoastrocytomas and 4 anaplastic pleomorphic xanthoastrocytomas). The preoperative MR imaging characteristics of these groups were statistically compared.

RESULTS: The wild-type pleomorphic xanthoastrocytoma group presented with more aggressive conventional and advanced MR imaging features than the mutant pleomorphic xanthoastrocytoma group, including greater mean maximum tumor diameter (3.1 $[\mathrm{SD}, 0.9] \mathrm{cm}$ versus $1.7[\mathrm{SD}, 0.4] \mathrm{cm}, P<.05)$, more frequent heterogeneous contrast enhancement of solid portions (100\% versus $0 \%, P<.001$ ), more obvious peritumoral edema (mean, $[2.1 \mathrm{SD}, 0.7] \mathrm{cm}$ versus $0.6[\mathrm{SD}, 0.2] \mathrm{cm}, P<.01$ ), and lower mean minimum relative ADC (896 [SD, 86] versus 988 [SD, 73], $P<.05)$ and mean relative ADC (1060 [SD, 159] versus 1248 [SD, 116], $P<.05)$ on DWI. However, there was no significant difference in either conventional or advanced MR imaging features between the wild-type anaplastic pleomorphic xanthoastrocytoma group and the mutant anaplastic pleomorphic xanthoastrocytoma group.
\end{abstract}

CONCLUSIONS: Neurosurgeons should carefully interpret MR images before an operation and select appropriate surgical strategies according to genotype prediction.

ABBREVIATIONS: $\mathrm{ADC}$ mean $=$ mean relative $\mathrm{ADC} ; \mathrm{ADC}$ in $=$ minimum relative $\mathrm{ADC} ; \mathrm{APXA}=$ anaplastic pleomorphic xanthoastrocytoma; $\mathrm{PXA}=$ pleomorphic xanthoastrocytoma; $\mathrm{WHO}=$ World Health Organization

$\mathbf{P}$ leomorphic xanthoastrocytoma (PXA) is an infrequent glioma affecting $1 \%$ of patients with brain tumors, thought to originate from subpial astrocytes or their precursors and usually occurring in children and adolescents. ${ }^{1}$ PXA was first described by Kepes et $\mathrm{al},{ }^{2}$

Received May 19, 2021; accepted after revision August 10.

From the Department of Neurosurgery (W.H., J.C., Y.X., H.W., Z.W., D.K.), The First Affiliated Hospital of Fujian Medical University, Fuzhou, Fujian, China; The First Clinical Medical College of Fujian Medical University (W.H., J.C., Y.X., H.W., Z.W., D.K.), Fuzhou, Fujian, China; and The School of Medical Technology and Engineering (N.L.), Fujian Medical University, Fuzhou, Fujian, China.

Wei Huang, Jiawei Cai, and Ni Lin contributed equally to this study.

This work was supported by the Natural Science Foundation of Fujian Province, 2018j01851 and the Science and Technology Projects of Fujian Province, 2020 GGA054.

Please address correspondence to Zanyi Wu, MD, Department of Neurosurgery, The First Affiliated Hospital of Fujian Medical University, 88 Jiaotong Rd, Fuzhou, Fujian 350005, China; e-mail: kirby98@126.com

- Indicates open access to non-subscribers at www.ajnr.org

http://dx.doi.org/10.3174/ajnr.A7324 in 1979. In 1993, it was officially included in the World Health Organization (WHO) Classification System for Tumors of the Central Nervous System as a grade II tumor. ${ }^{3}$ Although PXA is classified as a WHO grade II tumor, "PXA with anaplastic features" comprise $15 \%-50 \%$ of these lesions. ${ }^{4-7}$ According to the 2016 WHO classification system, PXA is divided into 2 distinct entities based on histopathologic characteristics: WHO grade II PXA and WHO grade III anaplastic PXA (APXA). ${ }^{8,9}$ APXA is defined as the presence of 5 mitoses per 10 high-power fields. Patients with PXA can undergo only total resection, while patients with APXA require total resection and adjuvant therapy. ${ }^{5,10}$ In addition, APXA has been reported to have a worse prognosis than PXA, with a 5-year overall survival rate of $57.1 \%{ }^{5,11,12}$

The most frequently found mutant gene in PXA is BRAF $p$. $V 600 E$, which encodes an intracellular component of the MAPK pathway. ${ }^{13-16}$ BRAF p. V600E-mutants were found in $70 \%$ of typical PXAs but appeared less commonly in APXA (17\%- 
65\%). ${ }^{5,13,17,18}$ BRAF p. V600E-mutant may divide these tumors into 2 clinically relevant subsets, both associated with natural history and response to treatment. ${ }^{19}$ Compared with the wildtype, BRAF p. V600E-mutant PXA showed a higher survival rate. ${ }^{5,20,21}$ BRAF p. V600E-mutant PXA has also shown a response to $B R A F$-targeted therapy, ${ }^{22}$ though no prospective comparative trials have been conducted in this patient population.

APXA can present with more aggressive conventional and advanced MR imaging features, mimicking high-grade astrocytoma at initial diagnosis, than PXA. ${ }^{23}$ However, there have been few reports on the MR imaging characteristics of PXA with BRAF $p$. V600E-mutant, especially its differentiation from BRAF p. V600E wild-type PXA. Therefore, the purpose of this study was to investigate the MR imaging characteristics of BRAF p. V600E-mutant PXA and BRAF p. V600E wild-type PXAs to determine whether there are differences in the imaging characteristics of these 2 entities to aid in planning a treatment strategy and predicting prognosis.

\section{MATERIALS AND METHODS \\ Case Selection}

The study was approved by the Branch for Medical Research and Clinical Technology Application, Ethics Committee of the First Affiliated Hospital of Fujian Medical University and informed consent was signed. Of 317 astrocytic tumor cases from January 2015 to December 2020, twenty-eight (0.89\%) with diagnoses containing the term "pleomorphic xanthoastrocytoma" or " anaplastic pleomorphic xanthoastrocytoma" on first surgical resection were extracted. Three (of 28) cases lacked MR imaging data before the first operation and were excluded. Twenty-five adult patients with PXA were included in this study, and a review of all their clinical and radiologic records was performed. The analyzed clinical information included sex, age, and symptoms (seizures, increased intracranial pressure, and neurologic deficits). These data were obtained from the electronic medical record system.

\section{Histopathologic and Molecular Sequencing}

Paraffin-embedded tumor tissue was cut into 4-mm sections and stained with $\mathrm{H} \& \mathrm{E}$, and $10-\mathrm{mm}$ sections were used for molecular sequencing. All histologic specimens were reviewed by our institutional neuropathologist (with 15 years of experience in neuropathology), who reclassified PXA (WHO grade II) and APXA (WHO grade III) according to the 2016 WHO classification of central nervous system tumors and the Consortium to Inform Molecular and Practical Approaches to CNS Tumor Taxonomy (cIMPACT-NOW) update $6 .^{24}$ The diagnostic criteria included tumors demonstrating a relatively solid growth pattern composed of spindle-shaped, pleomorphic, and multinucleated cells associated with both pale and bright eosinophilic granular bodies to be diagnosed as PXA. Anaplastic features, which included a mitotic index of 5 of 10 high-power fields with or without necrosis and endothelial proliferation, were diagnosed as APXA. Twenty-five patients were studied. Of these, 10 PXA and 13 APXA specimens were confirmed. We excluded 2 cases: One was reclassified as "diffuse astrocytoma, $I D H$ wild-type with pleomorphic/PXA-like features," and the other was previously diagnosed as "pleomorphic xanthoastrocytoma with anaplastic features" and reclassified as "giant cell glioblastoma." All 23 cases were available for molecular sequencing. Molecular analyses were performed to test the presence of the BRAF $p$. V600E-mutant, which was confirmed by sequencing. Of these, 11 BRAF p. V600E-mutant PXAs (including 6 cases of PXA and 5 cases of APXA) and 12 BRAF p. V600E wildtype PXAs (including 4 cases of PXA and 8 cases of APXA) were confirmed.

\section{Preoperative MR Imaging Techniques}

All patients underwent MR imaging on 3T scanners (Magnetom Verio or Magnetom Skyra; Siemens) or a $1.5 \mathrm{~T}$ scanner (Signa TwinSpeed; GE Healthcare). The retrospective nature of this study resulted in variability in MR images and imaging protocols. Conventional MR imaging protocols included an axial T2weighted sequence, nonenhanced axial and sagittal T1-weighted sequences, and 3 orthogonal plane contrast-enhanced T1weighted sequences. An FOV of $22 \mathrm{~cm}^{2}$, imaging matrix of $256 \times$ 256 , and section thickness of $5 \mathrm{~mm}$ were uniformly applied in all sequences.

DWI was performed in 10 patients with PXA and 13 patients with APXA using an axial echo-planar sequence according to the following technique parameters: TR/TE $=8200 / 102 \mathrm{~ms}$, FOV $=$ $22 \times 22 \mathrm{~cm}$, section thickness $/$ gap $=5 / 1 \mathrm{~mm}$, diffusion gradient encoding $=b=0,1000 \mathrm{~s} / \mathrm{mm}^{2}$. The diffusion gradient was used in 3 orthogonal directions. ADC maps were automatically calculated using a monoexponential model.

\section{MR Imaging Analysis}

All images were reviewed in consensus by 2 radiologists (readers 1 and 2 with 20 and 8 years of experience in neuroimaging, respectively) to make a factual comparison and minimize the confounding effects. The readers were blinded to tumor histology and recorded the following tumor characteristics: 1) tumor location (frontal, occipital, temporal, or parietal; superficial or deep); 2) tumor size (largest diameter, in centimeters); 3 ) the presence of cystic degeneration; 4) enhancement characteristics of the solid component (heterogeneous or homogeneous); 5) the presence and degree of peritumoral edema (largest diameter, in centimeters); 6) leptomeningeal contact; and 7) the presence of restricted diffusion, defined as high signal on DWI and corresponding low signal on ADC maps compared with contralateral normal brain parenchyma.

Tumor size was defined by the maximum diameter as measured on contrast-enhanced T1WI. The extent of peritumoral edema was defined by a region of very bright signal intensity on T2 surrounding the enhanced tumor on contrast-enhanced T1WI. The tumor location was defined as main lobe involvement when $>1$ lobe was involved.

For quantitative ADC evaluation, MR images were postprocessed as follows: 1) identification of the axial DWI and corresponding $\mathrm{ADC}$ image section displaying the lowest $\mathrm{ADC}$ values within solid tumor tissue components; 2) definition of a circular ROI of 6-mm diameter, manually drawn within the perceived lowest ADC solid tumor component, recording the minimum relative $\mathrm{ADC}(\mathrm{ADCmin})$ and mean relative $\mathrm{ADC}$ (ADCmean) values of this tumoral ROI (the ROI was systematically moved within the solid tumoral area, as depicted by conventional MR imaging, to measure regions with the lowest $\mathrm{ADC}$ values); 3) 
Table 1: Demographic data and conventional MR imaging characteristics of PXA and APXA

\begin{tabular}{lccc}
\hline & PXA & APXA & $P$ Value \\
\hline Clinical data & & & \\
Male sex (No.) (\%) & $3(30 \%)$ & $6(46.1 \%)$ & .363 \\
Mean age (yr) & $34(\mathrm{SD}, 10)$ & $41(\mathrm{SD}, 10)$ & .232 \\
Presenting symptoms (No.) & & & .899 \\
Seizures & 6 & 9 & \\
Headache or increased ICP & 2 & 2 & \\
Neurologic deficit & 2 & 2 & .273 \\
BRAFp. V600E-mutant & $6(60 \%)$ & $5(38.5 \%)$ & .526 \\
Location (No.) & & & \\
Frontal lobe & 0 & 3 & \\
Temporal lobe & 5 & 5 & .596 \\
Occipital lobe & 2 & 1 & \\
Parietal lobe & 2 & 3 & \\
Insula & $8(80 \%)$ & $11(84.6 \%)$ & .01 \\
Superficial location (No.) (\%) & & & .490 \\
Conventional MR imaging & $2.2(\mathrm{SD}, 0.9)$ & $3.2(\mathrm{SD}, 0.6)$ & .021 \\
Mean size (cm) & $6(60 \%)$ & $9(69.2 \%)$ & \\
Presence of cystic degeneration (No.) (\%) & $1.2(\mathrm{SD}, 0.8)$ & $2.1(\mathrm{SD}, 0.9)$ & .001 \\
Peritumoral edema (mean) (cm) & $4(40 \%)$ & $11(84.6 \%)$ & .596 \\
Heterogeneous enhancement (No.) (\%) & $8(80 \%)$ & $11(84.6 \%)$ & \\
Leptomeningeal contact (No.) (\%) &
\end{tabular}

Note:-ICP indicates intracranial pressure.

definition and assessment of the reference region minimum and mean ADC values, by placing a similar ROI on the normal-appearing thalamus (because it is a readily identifiable structure on ADC maps and is considered generally resistant to changes related to hydrocephalus); ${ }^{25}$ and 4) finally, the mean and minimum ADC values of the tumoral ROIs with the lowest ADC value were normalized with their corresponding reference region, obtaining ADCmean and ADCmin. This computation was performed because ADC values of normal brain vary with age, ${ }^{26}$ and the contrast achieved between tumor and surrounding tissue depends on this ratio; at the same time, this computation allowed data comparison of brain MR imaging performed with different scanners.

\section{Statistical Analysis}

The normality of all continuous parameters was initially assessed using the Kolmogorov-Smirnov test. Characteristics of the patients were summarized with means or medians and SDs or ranges for continuous data (as appropriate) and with frequencies and percentages for categoric data. The Fisher exact test was used to assess the differences in the categoric variables (age, sex, location, cystic degeneration, enhancement characteristics, and leptomeningeal contact) between the different groups. The Mann-Whitney $U$ test was used to assess the differences in continuous variables (edema, tumor size, and ADC values) between the different groups because they did not conform to the normal distribution.

The MR imaging differences between the BRAF p. V600Emutant PXA group and the BRAF $p$. V600E wild-type PXA group and the BRAF p. V600E-mutant APXA group and the BRAF $p$. V600E wild-type APXA group were statistically analyzed. Statistical analysis was performed with the Statistical Package for the Social Sciences (SPSS 24.0 Version for Windows; IBM). All reported $P$ values were double-tailed, and $P$ values less $<.05$ were regarded as statistically significant.

\section{RESULTS \\ Clinical Data and Conventional MR Imaging}

According to molecular analysis, 10 cases of PXA were divided into a BRAF p. V600E-mutant PXA group $(n=6)$ and a wild-type PXA group $(n=4) ; 13$ cases of APXA were divided into a BRAF p. V600E-mutant APXA group $(n=5)$ and a wild-type APXA group $(n=8)$. Clinical data, molecular analysis, location, and conventional imaging features of PXA and APXA are summarized in Table 1. All 23 tumors were in the supratentorial region. Eight PXAs (8/10, 80\%) and 11 APXAs $(11 / 13,84.6 \%)$ were superficial (on the surface of the brain parenchyma). There was no significant difference in tumor location between the PXA and APXA groups. The presence of heterogeneous enhancement of solid portions was observed less frequently in patients with PXA than in patients with APXA (4/10 versus 11/13, $P<.001)$. Leptomeningeal contact was seen in 8 PXA cases and 11 APXA cases. In preoperative images, the lesion was significantly larger in patients with APXA than in patients with PXA (mean, $3.2[\mathrm{SD}, 0.6] \mathrm{cm}$ versus $2.2[\mathrm{SD}, 0.9] \mathrm{cm}, P<.01)$. The average maximum diameter of peritumoral edema in the APXA group was larger than the average maximum diameter of peritumoral edema in the PXA group (2.1 [SD , 0.9] $\mathrm{cm}$ versus 1.2 [SD, 0.8] cm, $P=.021$ ) (Fig 1).

Table 2 and Table 3 summarize the clinical data, localization, and conventional imaging features of BRAF p. V600E subtypes of PXAs and APXAs, respectively. There was no significant difference in location between the BRAF V600E mutant and wild-type groups for either PXAs or APXAs. In preoperative images, the presence of heterogeneous enhancement of solid portions was observed less frequently in patients with BRAF p. V600E-mutant PXA than in patients with wildtype PXA $(0 / 6$ versus $4 / 4, P<.001)$. However, there was no significant difference in the presence of heterogeneous enhancement of the location of solid portions between the 2 groups in APXAs (5/5 versus 6/8, $P=.359$ ). The mean tumor size (the maximum diameter represents the size of the tumor) was significantly larger in patients with BRAF p. V600E wildtype PXA than in patients in the group with mutant PXA (3.1 [SD , 0.9] $\mathrm{cm}$ versus 1.7 [SD, 0.4] $\mathrm{cm}, P=.038$ ). The maximum diameter of peritumoral edema in the BRAF p. V600E wildtype PXA group was significantly larger than the mutant PXA group (mean, $2.1[\mathrm{SD}, 0.7] \mathrm{cm}$ versus $0.6[\mathrm{SD}, 0.2] \mathrm{cm}$, $P<.01)$. However, there was no significant difference in either mean tumor size $(3.3[\mathrm{SD}, 0.7] \mathrm{cm}$ versus $3.2[\mathrm{SD}, 0.5] \mathrm{cm}$, $P=.943)$ or the mean maximum diameter of peritumoral edema (2.4 [SD, 0.9] cm versus $1.8[\mathrm{SD}, 0.4] \mathrm{cm}, P=.3$ ) between the BRAF p. V600E-mutant type APXA group and the wild-type APXA group (Fig 2). 


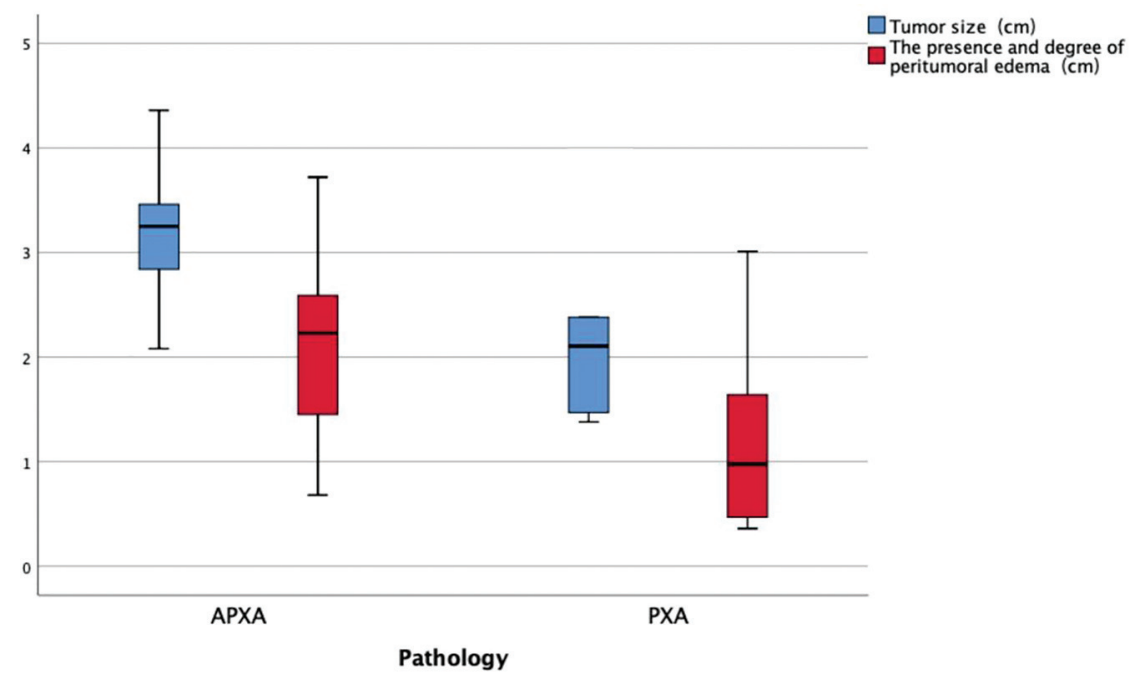

FIG 1. Boxplots representing tumor size and the presence and degree of peritumoral edema of PXA and APXA. A significant difference $(P<.05)$ between PXA and APXA is demonstrated with both tumor size and the presence and degree of peritumoral edema.

Table 2: Demographic data and conventional MR imaging characteristics of BRAF $p$. V600E-mutant and BRAF P. V600E wild-type PXA

\begin{tabular}{|c|c|c|c|}
\hline & $\begin{array}{l}\text { BRAF p. V600E- } \\
\text { Mutant PXA }\end{array}$ & $\begin{array}{l}\text { BRAF p. V600E Wild- } \\
\text { Type PXA }\end{array}$ & $\begin{array}{c}P \\
\text { Value }\end{array}$ \\
\hline \multicolumn{4}{|l|}{ Clinical data } \\
\hline Male sex (No.) (\%) & $2(33.3 \%)$ & $1(25 \%)$ & .667 \\
\hline Mean age (yr) & $32(\mathrm{SD}, 8.6)$ & 37(SD, 13) & .762 \\
\hline Presenting symptoms (No.) & & & .870 \\
\hline Seizures & 4 & 2 & \\
\hline Headache or increased ICP & 1 & 1 & \\
\hline Neurologic deficit & 1 & 1 & \\
\hline Location (No.) & & & .405 \\
\hline Frontal lobe & 0 & 0 & \\
\hline Temporal lobe & 3 & 2 & \\
\hline Occipital lobe & 0 & 1 & \\
\hline Parietal lobe & 2 & 0 & \\
\hline Insula & 1 & 1 & \\
\hline Superficial location (No.) (\%) & $4(66.6 \%)$ & 4 (100\%) & .333 \\
\hline \multicolumn{4}{|l|}{ Conventional MR imaging } \\
\hline Mean size $(\mathrm{cm})$ & $1.7(S D, 0.4)$ & $3.1(\mathrm{SD}, 0.9)$ & .038 \\
\hline $\begin{array}{l}\text { Presence of cystic degeneration } \\
\text { (No.) (\%) }\end{array}$ & $2(33.3 \%)$ & $4(100 \%)$ & .071 \\
\hline Peritumoral edema (mean) $(\mathrm{cm})$ & $0.6 \pm 0.2$ & $2.1 \pm 0.7$ & $<.01$ \\
\hline $\begin{array}{l}\text { Heterogeneous enhancement } \\
\text { (No.) (\%) }\end{array}$ & $0(0 \%)$ & $4(100 \%)$ & $<.001$ \\
\hline Leptomeningeal contact (No.) (\%) & $6(100 \%)$ & $2(50 \%)$ & .03 \\
\hline
\end{tabular}

Note:- ICP indicates intracranial pressure.

\section{Advanced MR Imaging Findings}

Table 4 and Figure 3 summarize the features of PXAs and APXAs with DWI. Both mean ADCmin values (755 [SD, 77] versus 951 [SD, 88]; $P<.001)$ and ADCmean values (956 [SD, 106] versus 1173 [SD, 159], $P<.001$ ) were significantly lower in the whole APXA group than in the PXA group. Both mean ADCmin values (896 [SD, 86] versus 988 [SD, 73], $P<.05$ ) and ADCmean values (1060 [SD, 159] versus 1248 [SD, 116], $P<.05$ ) were significantly lower in the whole group of BRAF $p$. V600E wild-type PXA than in mutant-PXA group. However, there was no significant difference in mean $\mathrm{ADCmin}$ (750 [SD, 73] versus 762 [SD, 92], $P=1$ ) and
ADCmean (974 [SD, 92] versus 925 [SD, 131], $P=.724)$ values between the 2 groups in APXAs (Fig 4, Tables 5 and 6). Representative cases are shown in Figure 5.

\section{DISCUSSION}

To the best of our knowledge, few studies have evaluated and compared the imaging features of BRAF p. V600E wild-type PXA and BRAF p. V600Emutant PXA. Our results show that PXAs with BRAF p. V600E wild-type show more aggressive MR imaging features than those with the BRAF $p$. V600E-mutant according to MR imaging features, namely, larger tumor size, more heterogeneous contrast enhancement, obvious peritumoral edema, lower $\mathrm{ADCmin}$, and lower ADCmean ratio on DWI.

PXA is histologically classified as a grade II astrocytoma according to the 2016 WHO classification of the central nervous system. ${ }^{8}$ The outcomes in cases of PXAs are relatively favorable, with 5- and 10-year overall survival rates of 75\%-81\% and $67 \%$ $70 \%$, respectively, after total resection. ${ }^{7,27}$ APXA is more likely to be derived from a previous PXA with the development of anaplastic histologic features. ${ }^{28}$ In the present study, APXA accounted for $56.5 \%$ of PXAs and showed anaplastic features. Findings comparable with the results reported by Hirose et $\mathrm{al}^{6}$ were that approximately $50 \%$ of PXAs showed anaplastic features.

The BRAF p. V600E-mutant is a distinctive genomic alteration of PXA and APXA. ${ }^{17,29,30}$ Previous studies demonstrated that BRAF p. V600E-mutant status is an independent prognostic factor 
after adjusting for anaplasia, age, sex, and initial symptoms. ${ }^{12}$ In the present study, approximately $60 \%$ of PXAs and $38.4 \%$ of APXAs showed a BRAF p. V600E-mutant, findings comparable with the results reported by Dias-Santagata et $\mathrm{al}^{13}$ that BRAF $p$. V600E-mutants are found in $70 \%$ of typical PXAs but appear less commonly in APXAs.

Most large case series have reported no sex predilection. However, the proportion of women in our series was much higher than the proportion of men. PXA most frequently occurred in young adults in our study, consistent with previous studies. $^{1,5,27}$ APXA was reported to be more common in older adults with a median age of 40-65 years. ${ }^{31-33}$ In our series, 9 of 13 patients with APXA were middle-aged adults with a mean age of

Table 3: Demographic data and conventional MR imaging characteristics of BRAF $p$. V600E-mutant and BRAF P. V600E wild-type APXA

\begin{tabular}{|c|c|c|c|}
\hline & $\begin{array}{l}\text { BRAF p. V600E- } \\
\text { Mutant APXA }\end{array}$ & $\begin{array}{c}\text { BRAF p. V600E } \\
\text { Wild-Type APXA }\end{array}$ & $\begin{array}{c}P \\
\text { Value }\end{array}$ \\
\hline \multicolumn{4}{|l|}{ Clinical data } \\
\hline Male sex (No.) (\%) & $3(60 \%)$ & $3(37.5 \%)$ & .413 \\
\hline Mean age (yr) & $33(S D, 13)$ & $43(S D, 6)$ & .284 \\
\hline Presenting symptoms (No.) & & & .850 \\
\hline Seizures & 3 & 6 & \\
\hline Headache or increased ICP & 1 & 1 & \\
\hline Neurologic deficit & 1 & 1 & \\
\hline Location (No.) & & & .276 \\
\hline Frontal lobe & 0 & 3 & \\
\hline Temporal lobe & 2 & 3 & \\
\hline Occipital lobe & 1 & 0 & \\
\hline Parietal lobe & 2 & 1 & \\
\hline Insula & 0 & 1 & \\
\hline Superficial location (No.) (\%) & $4(80.0 \%)$ & $7(87.5 \%)$ & .641 \\
\hline \multicolumn{4}{|l|}{ Conventional MR imaging } \\
\hline Mean size $(\mathrm{cm})$ & $3.2(S D, 0.5)$ & $3.3(\mathrm{SD}, 0.7)$ & .943 \\
\hline $\begin{array}{l}\text { Presence of cystic degeneration (No.) } \\
(\%)\end{array}$ & $3(60 \%)$ & $6(75 \%)$ & .343 \\
\hline Peritumoral edema (mean) $(\mathrm{cm})$ & $1.8(S D, 0.4)$ & $2.4(S D, 0.9)$ & .354 \\
\hline Heterogeneous enhancement (No.) (\%) & $5(100 \%)$ & $6(75 \%)$ & .359 \\
\hline Leptomeningeal contact (No.) (\%) & $4(80 \%)$ & $7(87.5 \%)$ & .641 \\
\hline
\end{tabular}

Note:- ICP indicates intracranial pressure.
44.67 years at their first presentation, which is consistent with findings in previous studies. ${ }^{27}$

The most common tumor location of PXA was the temporal lobe $(50.0 \%)$, which is in accordance with findings in previous studies. ${ }^{34,35}$ Our results show that the principal initial manifestation was seizures, which were observed in $60 \%$ and $69.2 \%$ of patients with PXA and APXA, respectively. These results correspond to findings that seizures were obviously related to tumor involvement of the temporal lobe in PXA. ${ }^{12}$ Almost all PXA and APXA tumors in our series showed a superficial location in the cerebral hemispheres with leptomeningeal contact. Both PXA and APXA are believed to develop from subpial astrocytes, which partly explains why these 2 tumors preferably arise from superficial cortical sites. ${ }^{2}$

In our study, we found that APXA shows more aggressive MR imaging features than PXA, namely, larger tumor size, more heterogeneous contrast enhancement, and obvious peritumoral edema, consistent with previously reported findings. ${ }^{23}$ BRAF $p$. V600E-mutant PXAs have been reported to show histologic heterogeneity and display pleomorphic giant cells, xanthomatous changes, and fascicular and storiform growth patterns. ${ }^{13}$ Purkait et $\mathrm{al}^{36}$ also proposed the possibility of a morphologic spectrum of BRAF p. V600E-mutant tumors with astroblastoma at one end and PXA at the other. We found that BRAF p. V600E wild-type PXA showed significantly different imaging characteristics from mutant PXA, including larger tumor size, more heterogeneous contrast enhancement, and obvious peritumoral edema, which suggests that
Tumor size (cm)

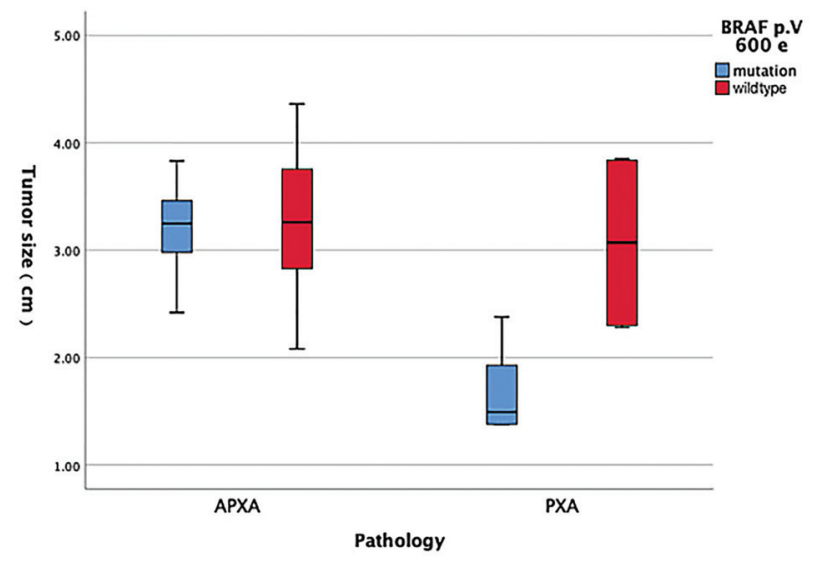

The presence and degree of peritumoral edema $(\mathrm{cm})$

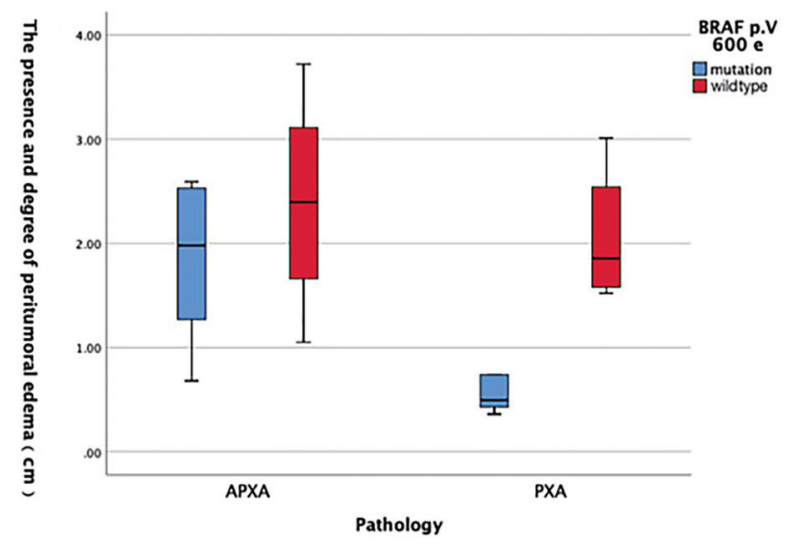

FIG 2. A significant difference $(P<.05)$ between the BRAF $p$. V600E-mutant type PXA group and the BRAF $p$. V600E wild-type PXA group is demonstrated with both tumor size and the presence and degree of peritumoral edema. However, there was no significant difference in both tumor size and the maximum diameter of peritumoral edema between the BRAF $p$. V600E-mutant type APXA group and BRAF $p$. V600E wildtype APXA group. 
BRAF p. V600E wild-type PXA may be more similar to high-grade gliomas in morphology. This conclusion may provide clinicians with strategies for tumor resection: For tumors identified by preoperative MR imaging such as BRAF p. V600E wild-type, more aggressive and expanded resection may be performed. For BRAF $p$. V600E-mutant tumors judged by preoperative MR imaging, a relatively conservative treatment strategy should be adopted, especially if the tumors are located in functional areas.

Table 4: Advanced MR imaging characteristics of the PXA and APXA groups

\begin{tabular}{lccc}
\hline & PXA & APXA & P Value \\
\hline ADCmin $\left(\times 10^{-6} \mathrm{~mm}^{2} / \mathrm{s}\right)$ & $951(\mathrm{SD}, 88)$ & $755(\mathrm{SD}, 77)$ & $<.001$ \\
ADCmean $\left(\times 10^{-6} \mathrm{~mm}^{2} / \mathrm{s}\right)$ & $1173(\mathrm{SD}, 159)$ & $956(\mathrm{SD}, 106)$ & $<.001$ \\
\hline
\end{tabular}

In the present study, we demonstrate that the rate of water diffusion of APXA, as reflected by the ADC ratio, was significantly lower than the rate of water diffusion of PXA, consistent with previous studies. Compared with BRAF p. V600E-mutant PXA, the ADC value of wild-type PXA was significantly lower. These results might be due to markedly high cellularity and a high nuclear/cytoplasmic ratio. Therefore, our findings reveal that ADC could be a useful imaging parameter for assessing the differences between BRAF $p$. V600E-mutant PXA and wild-type PXA. Only a few prior studies in the literature evaluated PXA using DWI. ${ }^{37}$ The results of this study underline the usefulness of this simple imaging biomarker for radiogenomic correlation. However, future investigations are needed to better define the relationship between DWI features of BRAF p. V600E-mutant PXA and tumoral microarchitecture.

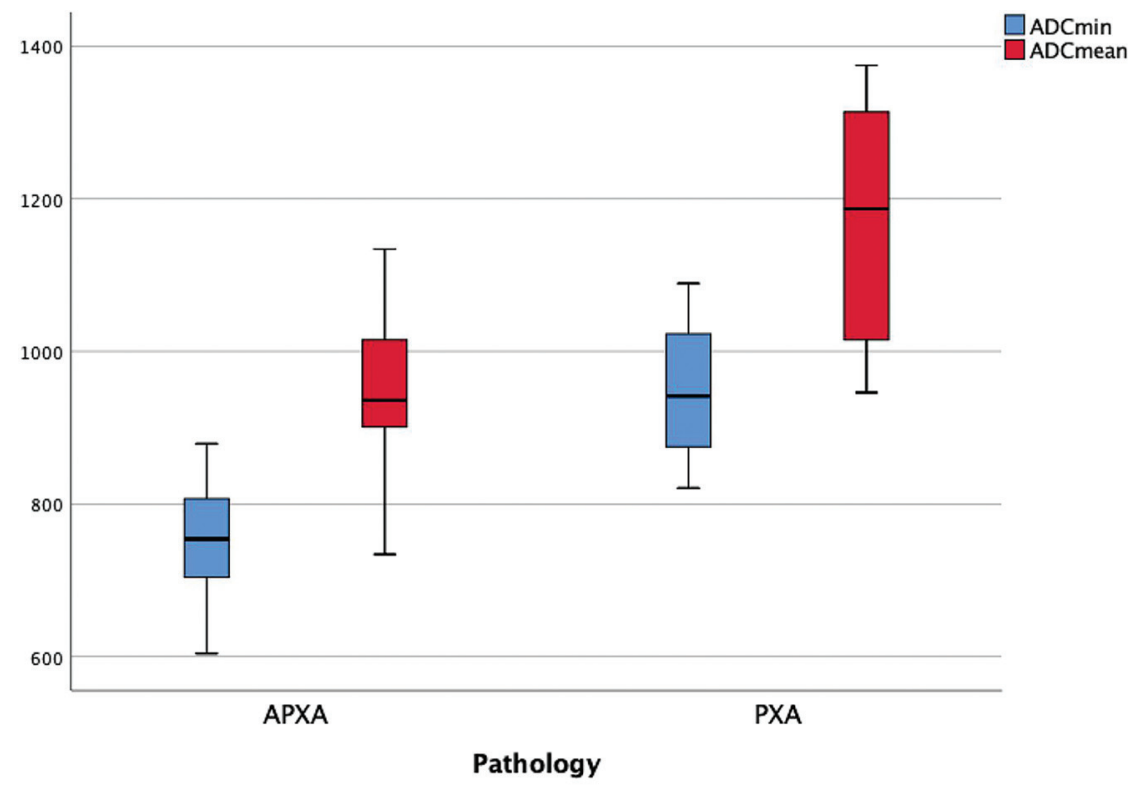

FIG 3. Boxplots representing ADCmin and ADCmean of PXA and APXA. A significant difference $(P<.05)$ between PXA and APXA is demonstrated with both $A D C m i n$ and $A D C$ mean.

ADCmin

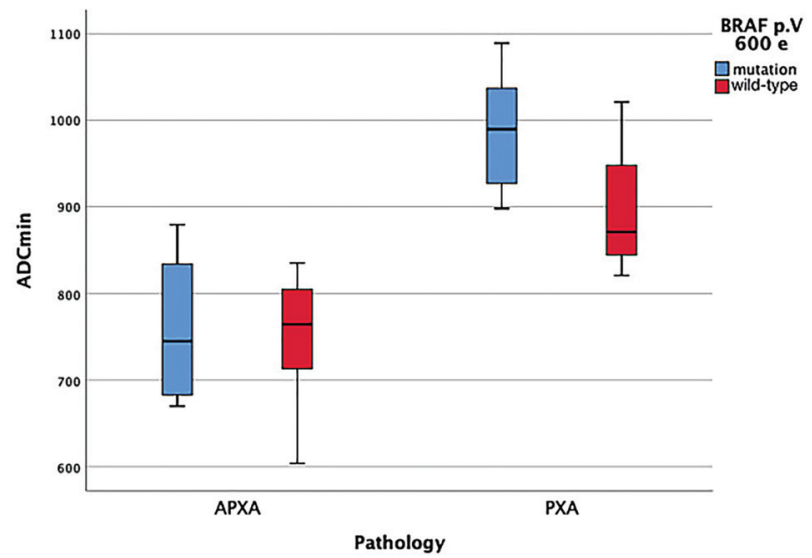

ADCmean

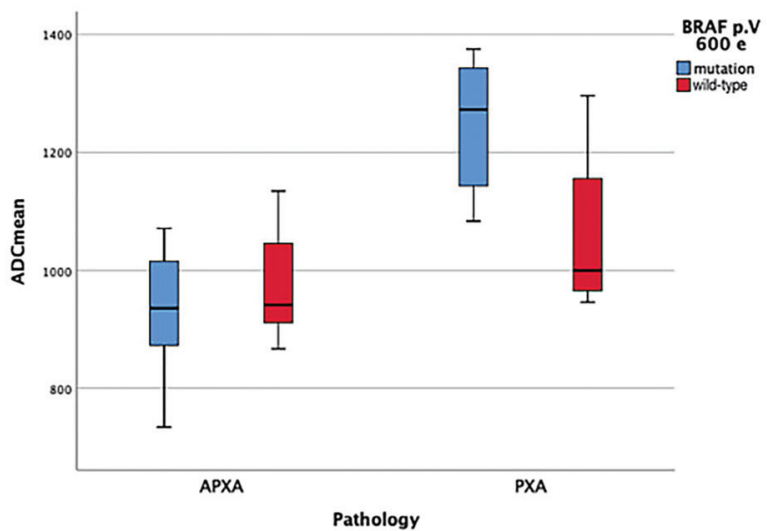

FIG 4. A significant difference $(P<.05)$ between the BRAF $p$. V600E-mutant type PXA group and the BRAF $p$. V600E wild-type PXA group is demonstrated with both $A D C$ min and ADCmean. However, there was no significant difference in both ADCmin and ADCmean between the BRAF p. V600E-mutant type APXA group and BRAF p. V600E wild-type APXA group. 
Table 5: Advanced MR imaging characteristics of the BRAF $p$. V600E-mutant PXA and BRAF P. V600E wild-type PXA groups

\begin{tabular}{lccc}
\hline & $\begin{array}{c}\text { BRAF } p . \\
\text { V600E- } \\
\text { Mutant PXA }\end{array}$ & $\begin{array}{c}\text { BRAF } p . \\
\text { V600E Wild- } \\
\text { Type PXA }\end{array}$ & $\begin{array}{c}\boldsymbol{P} \\
\text { Value }\end{array}$ \\
\hline ADCmin $\left(\times 10^{-6} \mathrm{~mm}^{2} / \mathrm{s}\right)$ & $988(\mathrm{SD}, 73)$ & $896(\mathrm{SD}, 86)$ & .047 \\
$\mathrm{ADCmean}\left(\times 10^{-6} \mathrm{~mm}^{2} / \mathrm{s}\right)$ & $1248(\mathrm{SD}, 116)$ & $1060(\mathrm{SD}, 159)$ & .049 \\
\hline
\end{tabular}

Table 6: Advanced MR imaging characteristics of the BRAF $p$. V600E-mutant APXA and BRAF P. V600E wild-type APXA groups

\begin{tabular}{lccc}
\hline & BRAF $p$. & & \\
& V600E- & BRAF $p$. & \\
& Mutant & V600E Wild- & $\boldsymbol{P}$ \\
& APXA & Type APXA & Value \\
\hline ADCmin $\left(\times 10^{-6} \mathrm{~mm}^{2} / \mathrm{s}\right)$ & $762(\mathrm{SD}, 92)$ & $750(\mathrm{SD}, 73)$ & 1 \\
ADCmean $\left(\times 10^{-6} \mathrm{~mm}^{2} / \mathrm{s}\right)$ & $925(\mathrm{SD}, 131)$ & $974(\mathrm{SD}, 92)$ & .724 \\
\hline
\end{tabular}

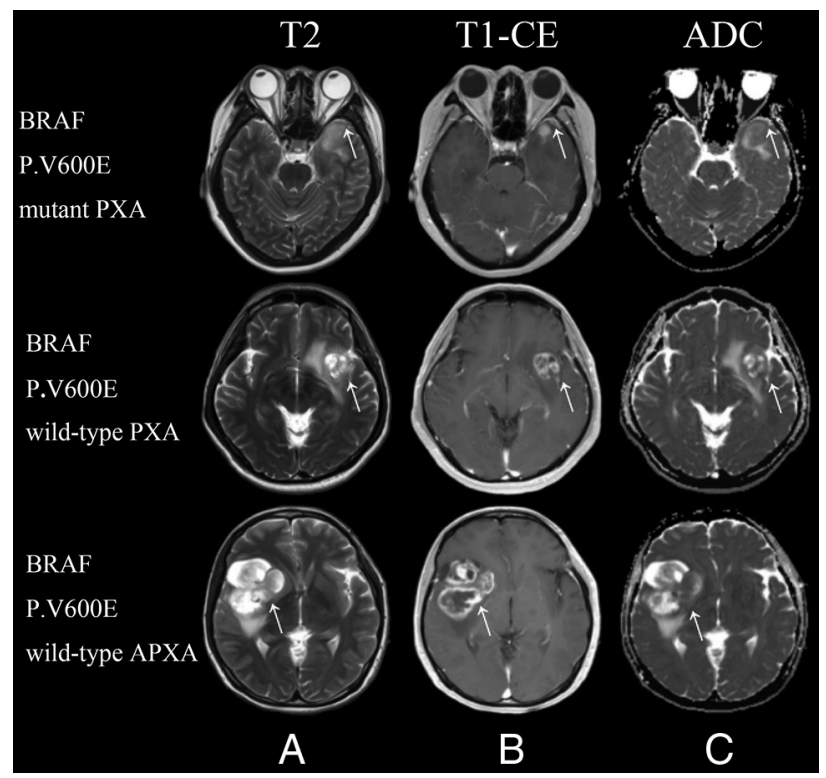

FIG 5. Conventional and advanced MR images of BRAF $p$. V600Emutant and wild-type PXA. Upper row: A 27-year-old female patient with a BRAF p. V600E-mutant pleomorphic astrocytoma. T2WI (A) and contrast-enhanced TIWI $(B)$ show a homogeneous contrastenhancing solid tumor with mild perilesional edema located in the temporal lobe. $C$, A correlative $A D C$ map shows the tumor with an elevated $A D C$ value $(A D C m i n=1089)$. Second row: $A$ 53-year-old male patient with a BRAF $p$. V600E wild-type pleomorphic astrocytoma. T2WI (A) and contrast-enhanced TIWI (B) show a heterogeneous contrast-enhancing tumor with cystic degeneration and marked perilesional edema located in the insula. $C$, A correlative ADC map shows the lesion with a decreased $A D C$ value $(A D C m i n=875)$. Third row: A 46-year-old female patient with a BRAF $p$. V600E wild-type anaplastic pleomorphic astrocytoma. T2WI (A) and contrastenhanced TIWI $(B)$ show a heterogeneous contrast-enhancing tumor with cystic degeneration and marked perilesional edema located in the insula. C, A correlative ADC map shows the lesion with diffusion restriction $(A D C \min =704)$. $C E$ indicates contrast-enhanced.

We did not find any MR imaging differences between the BRAF p. V600E-mutant APXA and the wild-type, whether using conventional or advanced imaging, possibly because the imaging features of APXA itself, similar to the imaging features of highgrade astrocytomas, mask the differences caused by BRAF $p$.
V600E-mutant. Vuong et $\mathrm{al}^{20}$ previously proposed that BRAF $p$. V600E only showed a significant improvement in patient survival in low-grade tumors. These results illustrate the limitations of the BRAF p. V600E-mutant on MR imaging morphologic and clinical outcomes of APXA.

Several potential limitations of this study should be mentioned. First, our research is a single-center observational retrospective study. The influence caused by the deviation of the retrospective study cannot be excluded. Second, although the sample size included in this study is relatively large among the reports on PXA thus far, the number of patients in our study remained limited, whether it was PXA or APXA, BRAF $p$. V600E-mutant or wild-type. Therefore, the conclusions should be interpreted with caution. Third, because ADC values were not used to guide the biopsy in this retrospective study, it was not possible to evaluate the correlations between regions of lower ADC in PXA and hypercellularity point to point. These correlations should be performed in our future study. Larger multicenter prospective studies are necessary to perform an accurate analysis of the relationship between imaging features and genomic characteristics of this rare tumor.

\section{CONCLUSIONS}

BRAF p. V600E wild-type PXA can present with more aggressive conventional and advanced MR imaging features, mimicking high-grade astrocytomas at initial diagnosis, than $B R A F$ p. V600E-mutant PXA. Greater maximum tumor diameter, heterogeneous contrast enhancement, obvious peritumoral edema, and lower ADCmin and ADCmean are more common features in BRAF p. V600E wild-type PXA compared with BRAF p. V600E-mutant PXA. Neurosurgeons should carefully interpret MR images before an operation in cases that may be considered PXA and select an appropriate surgical strategy according to the prediction of BRAF $p$. V600E genotype.

Disclosure forms provided by the authors are available with the full text and PDF of this article at www.ajnr.org.

\section{REFERENCES}

1. Rao AA, Laack NN, Giannini C, et al. Pleomorphic xanthoastrocytoma in children and adolescents. Pediatr Blood Cancer 2010;55:29094 CrossRef Medline

2. Kepes JJ, Rubinstein LJ, Eng LF. Pleomorphic xanthoastrocytoma: a distinctive meningocerebral glioma of young subjects with relatively favorable prognosis-a study of $\mathbf{1 2}$ cases. Cancer 1979;44:1839-52

3. Kleihues P, Burger PC, Scheithauer BW. The new WHO classification of brain tumors. Brain Pathol 1993;3:255-68 CrossRef Medline

4. Louis DN, Ohgaki H, Wiestler OD, et al. The 2007 WHO classification of tumors of the central nervous system. Acta Neuropathol 2007;114:97-109 CrossRef Medline

5. Ida CM, Rodriguez FJ, Burger PC, et al. Pleomorphic xanthoastrocytoma: natural history and long-term follow-up. Brain Pathol 2015;25:575-86 CrossRef Medline

6. Hirose T, Ishizawa K, Sugiyama K, et al. Pleomorphic xanthoastrocytoma: a comparative pathological study between conventional and anaplastic types. Histopathology 2008;52:183-93 CrossRef Medline

7. Giannini C, Scheithauer BW, Burger PC, et al. Pleomorphic xanthoastrocytoma: what do we really know about it? Cancer 1999;85:2033-45 
8. Louis DN, Perry A, Reifenberger G, et al. The 2016 World Health Organization Classification of Tumors of the Central Nervous System: a summary. Acta Neuropathol 2016;131:803-20 CrossRef Medline

9. Wesseling P, Capper D. WHO 2016 classification of gliomas. Neuropathol Appl Neurobiol 2018;44:139-50 CrossRef Medline

10. Marton E, Feletti A, Orvieto E, et al. Malignant progression inpleomorphic xanthoastrocytoma: personal experience and review of the literature. J Neurol Sci 2007;252:144-53 CrossRef Medline

11. Rutkowski MJ, Oh T, Niflioglu GG, et al. Pleomorphic xanthoastrocytoma with anaplastic features: retrospective case series. World Neurosurg 2016;95:368-74 CrossRef Medline

12. Ma $\mathrm{C}$, Feng $\mathrm{R}$, Chen $\mathrm{H}$, et al. BRAF V600E, TERT, and IDH2 mutations in pleomorphic xanthoastrocytoma: observations from a large case-series study. World Neurosurg 2018;120:e122533 CrossRef Medline

13. Dias-Santagata D, Lam Q, Vernovsky K, et al. BRAF V600E mutations are common in pleomorphic xanthoastrocytoma: diagnostic and therapeutic implications. PLoS One 2011;6:e17948 CrossRef Medline

14. Tatevossian RG, Lawson AR, Forshew T, et al. MAPK pathway activation and the origins of pediatric low-grade astrocytomas. J Cell Physiol 2010;222:509-14 CrossRef Medline

15. Jacob K, Quang-Khuong DA, Jones DT, et al. Genetic aberrations leading to MAPK pathway activation mediate oncogene-induced senescence in sporadic pilocytic astrocytomas. Clin Cancer Res 2011;17:4650-60 CrossRef Medline

16. Maurer G, Tarkowski B, Baccarini M. Raf kinases in cancer: roles and therapeutic opportunities. Oncogene 2011;30:3477-88 CrossRef Medline

17. Schindler G, Capper D, Meyer J, et al. Analysis of BRAF V600E mutation in 1,320 nervous system tumors reveals high mutation frequencies in pleomorphic xanthoastrocytoma, ganglioglioma and extra-cerebellar pilocytic astrocytoma. Acta Neuropathol 2011;121:397-405 CrossRef Medline

18. Chamberlain MC. Salvage therapy with BRAF inhibitors for recurrent pleomorphic xanthoastrocytoma: a retrospective case series. $J$ Neurooncol 2013;114:237- 40 CrossRef Medline

19. Tabouret E, Bequet C, Denicolaï E, et al. BRAF mutation and anaplasia may be predictive factors of progression-free survival in adult pleomorphic xanthoastrocytoma. Eur J Surg Oncol 2015;41:1685-90 CrossRef Medline

20. Vuong HG, Altibi AM, Duong UN, et al. BRAF mutation is associated with an improved survival in glioma-a systematic review and meta-analysis. Mol Neurobiol 2018;55:3718-24 CrossRef Medline

21. Tonse R, Gupta T, Epari S, et al. Impact of WHO 2016 update of brain tumor classification, molecular markers and clinical outcomes in pleomorphic xanthoastrocytoma. J Neurooncol 2018;136:343-50 CrossRef Medline

22. Brown NF, Carter T, Kitchen N, et al. Dabrafenib and trametinib in BRAFV600E mutated glioma. CNS Oncol 2017;6:291-96 CrossRef Medline
23. She D, Liu J, Xing Z, et al. MR imaging features of anaplastic pleomorphic xanthoastrocytoma mimicking high-grade astrocytoma. AJNR Am J Neuroradiol 2018;39:1446-52 CrossRef Medline

24. Louis DN, Wesseling P, Aldape K, et al. cIMPACT-NOW update 6: new entity and diagnostic principle recommendations of the cIMPACT-Utrecht meeting on future CNS tumor classification and grading. Brain Pathol 2020;30:844-56 CrossRef Medline

25. Gimi B, Cederberg K, Derinkuyu B, et al. Utility of apparent diffusion coefficient ratios in distinguishing common pediatric cerebellar tumors. Acad Radiol 2012;19:794-800 CrossRef Medline

26. Mukherjee P, Miller JH, Shimony JS, et al. Normal brain maturation during childhood: developmental trends characterized with diffusion-tensor MR imaging. Radiology 2001;221:349-58 CrossRef Medline

27. Perkins SM, Mitra N, Fei W, et al. Patterns of care and outcomes of patients with pleomorphic xanthoastrocytoma: a SEER analysis. $J$ Neurooncol 2012;110:99-104 CrossRef Medline

28. Yan J, Cheng J, Liu F, et al. Pleomorphic xanthoastrocytomas of adults: MRI features, molecular markers, and clinical outcomes. Sci Rep 2018;8:14275 CrossRef Medline

29. Yang RR, Aibaidula A, Wang WW, et al. Pediatric low-grade gliomas can be molecularly stratified for risk. Acta Neuropathol 2018;136:641-55 CrossRef Medline

30. Lindsay AJ, Rush SZ, Fenton LZ. Pediatric posterior fossa ganglioglioma: unique MRI features and correlation with BRAF V600E mutation status. J Neurooncol 2014;118:395-404 CrossRef Medline

31. Ostrom QT, Gittleman H, Liao P, et al. CBTRUS Statistical Report: Primary brain and other central nervous system tumors diagnosed in the United States in 2010-2014. Neuro Oncol 2017;19:v1-88 CrossRef Medline

32. Thakkar JP, Dolecek TA, Horbinski C, et al. Epidemiologic and molecular prognostic review of glioblastoma. Cancer Epidemiol Biomarkers Prev 2014;23:1985-96 CrossRef Medline

33. Rasmussen BK, Hansen S, Laursen RJ, et al. Epidemiology of glioma: clinical characteristics, symptoms, and predictors of glioma patients grade I-IV in the Danish Neuro-Oncology Registry. $J$ Neurooncol 2017;135:571-79 CrossRef Medline

34. Yu S, He L, Zhuang X, et al. Pleomorphic xanthoastrocytoma: MR imaging findings in 19 patients. Acta Radiol 2011;52:223-28 CrossRef Medline

35. Crespo-Rodriguez AM, Smirniotopoulos JG, Rushing EJ. MR and CT imaging of 24 pleomorphic xanthoastrocytomas (PXA) and a review of the literature. Neuroradiology 2007;49:307-15 CrossRef Medline

36. Purkait S, Bansal S, Malgulwar PB. BRAF V600E-mutated central nervous system tumor with divergent morphological feature: anaplastic pleomorphic xanthoastrocytoma-like and astroblastomalike. Neuropathology 2019;39:64-67 CrossRef Medline

37. Moore W, Mathis D, Gargan L, et al. Pleomorphic xanthoastrocytoma of childhood: MR imaging and diffusion MR imaging features. AJNR Am J Neuroradiol 2014;35:2192-96 CrossRef Medline 